Jurnal Laut Khatulistiwa, Vol. 3 No. 3 (Oktober, 2020), Hal. 105-112.

\title{
Struktur Komunitas dan Laju Produksi Karbon Serasah Daun Mangrove di Kuala Singkawang
}

\section{Structure Community and The Rate of Production of Carbon MangroveLeaf Litter in Kuala Singkawang}

\author{
Nursofiati $^{1 *}$, Arie Antasari Kushadiwijayanto ${ }^{1}$, Ikha Safitri ${ }^{1}$ \\ ${ }^{1}$ Laboratorium Ilmu Kelautan, FMIPA Universitas Tanjungpura, Pontianak, Indonesia \\ ${ }^{*}$ E-mail : nursofiati7@gmail.com
}

Received : 9 Oktober Accepted : 25 Oktober 2020

Published : 31 Oktober 2020 (C) Author(s) 2020. This article is open access

\begin{abstract}
Mangrove ecosystem has important ecological function in efforts mitigate global warming, by carbon storage. The purpose of this research was to know about the community stucture mangrove and the rate of production of carbon mangrove leaf litter in Kuala Singkawang Kalimantan Barat. Each transect contain plots with each size was $10 \times 10$ meters. Transect size was $5 \times 5$ meters tand size was $2 \times 2$ meters. It show four kind of mangrove $A$. lanata, A. marina, $R$. apiculata, $R$. mucronata and the result showed that the average litter production of gram wet weigh $(G b b)$ and gram dry weight obtained during the study were 135,88 $\mathrm{gbb} / \mathrm{m}^{2}$ and 87,65 $\mathrm{gbk} / \mathrm{m}^{2} / 15 \mathrm{hr}$. Based on these result the amount of carbonr emoval in mangrove leaves was $70,82 \mathrm{~g} / \mathrm{C} / 15 \mathrm{hr}$ and $4,72 \mathrm{~g} / \mathrm{C} / 15 \mathrm{hr}$.
\end{abstract}

Keywords : mangrove ecosystem, comunity stucture, and carbon.

\begin{abstract}
Abstrak
Ekosistem mangrove memiliki fungsi ekologis yang penting dalam upaya mitigasi pemanasan global yaitu sebagai penyerap karbon. Tujuan dari penelitian iniadalah untuk mengetahui struktur komunitas dan laju produksi karbon dari serasah daun mangrove di Kuala Singkawang Kalimantan Barat. Penelitian ini menggunakan transek kuadran untuk ukuran $10 \mathrm{~m}$ x $10 \mathrm{~m}$ untuk tingkat pohon, $5 \mathrm{~m}$ x $5 \mathrm{~m}$ untukan tingkat pancang, $2 \mathrm{mx} 2 \mathrm{~m}$ untuk tingkat semai dan metode litter-trap yang berukuran $1 \mathrm{~m} \times 1 \mathrm{~m}$, sebanyak 2 buah dipasang setiap plot di stasiun I, II, dan III. Pengamatan dilakukan selama 15 hari. Hasil penelitian diperoleh terdapat 4 jenis mangrove yaitu A. marina, A. lanata, R.mucronata, $R$. apiculata dan rata-rata produksi serasah gram berat basah (Gbb) dan gram berat kering (Gbk) selama penelitian sebesar $135,88 \mathrm{gbb} / \mathrm{m}^{2}$ dan $87,65 \mathrm{gbk} / \mathrm{m}^{2} / 15 \mathrm{hr}$. Jumlah simpanankarbon tertinggi pada serasah daun mangrove sebesar 70,82 $\mathrm{g} / \mathrm{C} / 15 \mathrm{hr}$ dan $4,72 \mathrm{~g} / \mathrm{C} / 15 \mathrm{hr}$.
\end{abstract}

Kata kunci : ekosistem mangrove, struktur komunitas dan karbon.

\section{Pendahuluan}

Perairan Mangrove merupakan salah satu ekosistem pesisir perairan tropis yang memiliki tingkat produktivitas primer tinggi mencapai 2.700 gr $\mathrm{C} / \mathrm{m}^{2} /$ tahun (Supriharyono, 2017), dimana sepertiga bagian dari produktivitas primer tersebut berasal dari serasah yang jatuh (Alongi et al., 2005). Ekosistem mangrove berperan penting sebagai tempat mencari makan (feeding ground), pemijahan (spawning ground), dan pembesaran (nursery ground) berbagai jenis biota akuatik (Rangkuti et al., 2017). Hutan mangrove memiliki kemampuan menyerap karbon tiga kali lebih besar dibandingkan ratarata penyimpanan karbon per hektar oleh hutan tropis daratan (Mcleod et al., 2006; Donato et al., 2011). Penelitian sebelumnya menunjukan bahwa penyerapan karbon dari atmosfer oleh hutan mangrove berkisar 100 ton $\mathrm{CO}_{2}$ /ha (Maiti and Chowdury, 2013).

Selama 50 tahun terakhir, sekitar sepertiga 
luasan hutan mangrove di dunia mengalami kerusakan akibat aktivitas manusia (Alongi, 2002). Serasah merupakan salah satu komponen penting dalam estimasi produktivitas primer di kawasan hutan mangrove (Bunt, 1995; Metcalfe et al., 2011), dan merupakan sumber karbon penting dalam proses dekomposisi (Dharmawan et al., 2016).

Peneliian ini dilakukan untuk mengetahui struktur komunitas dan laju produksi karbon serasah daun mangrove di Kuala Singkawang Kalimantan Barat. Penelitian struktur komunitas dan laju produksi karbon serasah daun mangrove di Kuala Singkawang Kalimantan Barat diperlukan sebagai bahan informasi mengenai struktur komunitas dan laju produksi karbon serasah daun mangrove bagi Pemerintah Daerah sebagai bahan pertimbangan dalam pengelolaan ekosistem mangrove secara berkelanjutan di Kuala Singkawang Klaimantan Barat.

\section{Metodologi Penelitian}

Penelitian ini dilakukan pada bulan Januari sampai Februari 2020 di Kuala Singkawang Kalimantan Barat (Gambar 1). Penentuan stasiun dilakukan dengan metode purpossive sampling. Untuk stasiun I panjang transek yang digunakan $130 \mathrm{~m}$, stasiun II panjang transek $80 \mathrm{~m}$ dan stasiun III panjang transek $300 \mathrm{~m}$.
Pada stasiun I terdapat 3 plot, stasiun II terdapat 2 plot dan stasiun III terdapat 5 plot. Setiap plot dipasang 2 litter-trap, produksi penangkap serasah dilakukan selama 15 hari dengan 5 kali pengulangan dengan pengambilan 3 hari sekali (Hamidy et al., 2002).

Kondisi ekosistem mangrove digambarkan dengan kondisi keanekaragaman jenis, kerapatan jenis $(\mathrm{K})$, kerapatan relatif jenis (KR), frekuensi jenis (F), Frekuensi Relatif jenis (FR), dominansi jenis (D),

Kerapatan relatif jenis (KR), frekuensi jenis (F), Frekuensi Relatif jenis (FR), dominansi jenis (D), dominansi relatif (DR) dan nilai penting (NP).

$$
\begin{aligned}
& \mathrm{K}=\frac{\sum I S P}{L p} \\
& \mathrm{KR}=\frac{K S j}{K S S} \times 100 \% \\
& \mathrm{~F}=\frac{\sum I S P}{\Sigma T j p} \\
& \mathrm{FR}=\frac{f s j}{f s s} \times 100 \% \\
& \mathrm{D}=\frac{L b}{L p} \\
& \mathrm{DR}=\frac{D s}{D S S} \times 100 \% \\
& \mathrm{INP}=\mathrm{KR}+\mathrm{FR}+\mathrm{DR}
\end{aligned}
$$

\section{Keterangan :}

ISP = Individu suatu jenis

$\mathrm{Lp}=$ Luas petak contoh
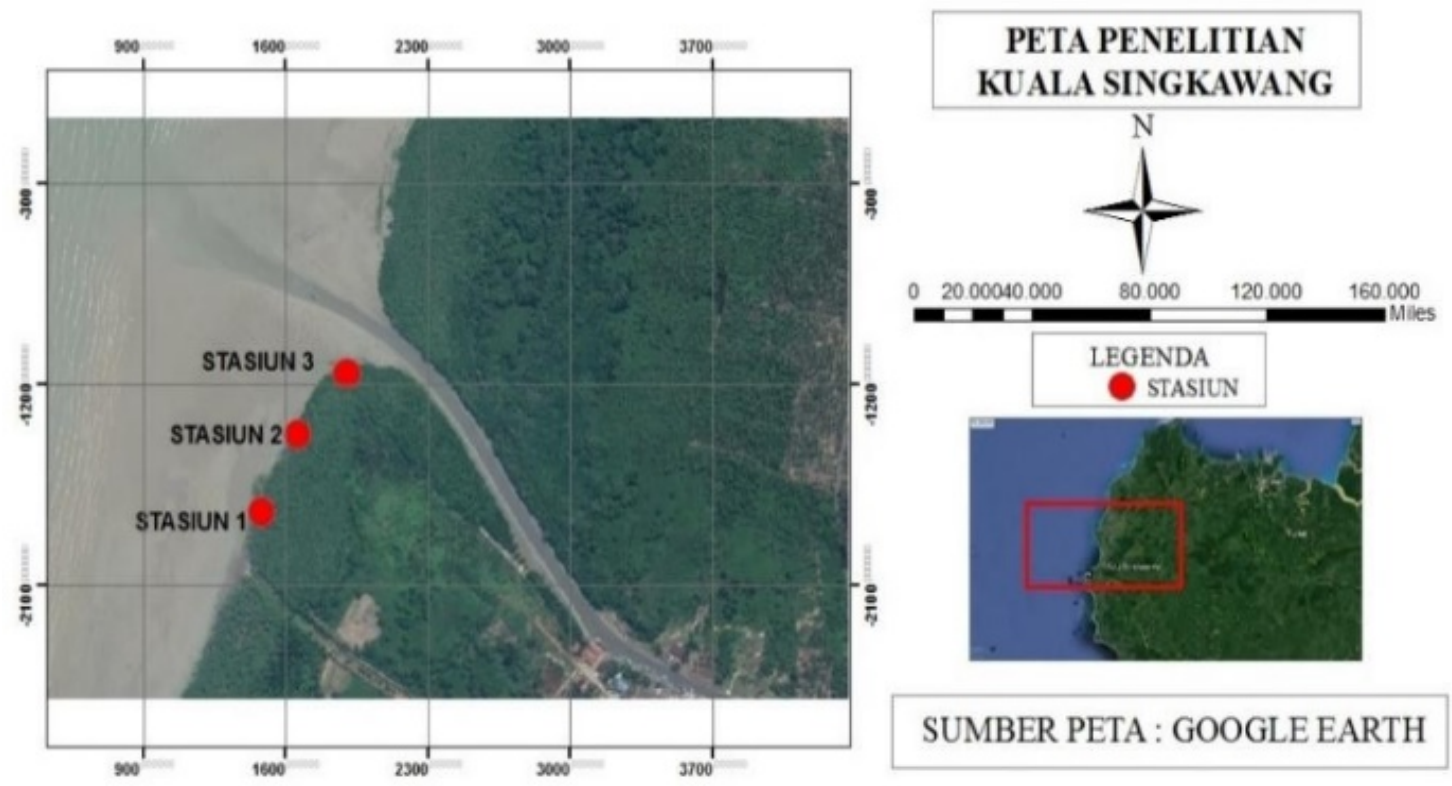

Gambar. Peta lokasi penelitian 
Jurnal Laut Khatulistiwa, Vol. 3. No. 3 (Oktober, 2020), Hal. 105-112.

Ksj = Kerapatan suatu jenis

Kss $=$ Kerapatan seluruh spesies

Tjp = Total jenis pada plot

$\mathrm{f} s \mathrm{j}=$ Frekuensi suatu jenis

$\mathrm{f}$ ss $=$ Frekuensi seluruh jenis

$\mathrm{Lb}=$ Luas bidang dasar suatu spesies

$\mathrm{Lp}=$ Luas petak contoh

Ds = Dominansi suatu spesies

Dss $=$ Dominansi seluruh spesies

Untuk karbon serasah daun mangrove berat sersah basah sebelum dioven ditimbang dan dikeringkan pada suhu $80^{\circ} \mathrm{C}$ selama 24 jam. Ditimbang kembali beratnya.

Dilanjutkan dengan metode pengabuan secara langsung (kering) selama 5 jam pada suhu berkisar antara $500-600^{\circ} \mathrm{C}$. Adapun langkah analisis kadar abu adalah sebagai berikut (Sudarmadji, 1996) :

1. Disiapkan cawan kosong sebagai tempat sampel dan ditimbang beratnya (B).

2. Sampel serasah yang sudah diketahui berat keringnya (C) dimasukan dalam cawan yang telah diketahui beratnya.

3. Cawan yang berisi sampel serasah dimasukan dalam muffle furnace dengan suhu $500-600^{\circ} \mathrm{C}$.

4. Sesudah 5 jam, sampel dikeluarkan dari oven pembakaran. Sampel didinginkan selama 1 jam kemudian ditimbang kembali untuk mengetahui berat akhir (A).

5. Setelah nilai kadar bahan kering serasah dan kadar abu didapatkan maka kandungan karbon dapat diketahui.

Adapun perhitungan yang digunakan untuk mengetahui kadar air,kadar bahan kering, kadar abu, dan kandungan karbon sebagai berikut :

Kadar air $=\frac{(A-B)}{A} \times 100 \%$

Keterangan :

$A=$ Berat basah serasah (gram)

$\mathrm{B}=$ Berat kering serasah

Kadar bahan kering serasah $=$

(100- kadar air)\%

Kadar abu $=\frac{(A-B)}{C} \times 100 \%$

Keterangan :

A = Berat akhir cawan+sampel

$\mathrm{B}=$ Berat awal cawan

$\mathrm{C}=$ Berat sampel (gram)

\section{Hasil dan Pembahasan}

Proses hasil pengamatan dan identifikasi berdasarkan ciri morfologi mangrove diperoleh sebanyak 4 spesies yaitu Avicennia marina, A. lanata, Rhizopora apiculata, $R$. mucronata. Tegakan tumbuhan mangrove sangat berkaitan erat dengan penguasaan tempat yang dipengaruhi oleh besarnya cahaya matahari yang didapatkan serta ketersediaan air tanah dan unsur hara untuk pertumbuhan mangrove (Setiawan dan Mursidin, 2018).

\subsection{Komposisi jenis mangrove tingkat pohon}

Pada lokasi penelitian, persentase tertinggi jenis mangrove tingkat pohon adalah A. marina $82,56 \%$ dan persentase terendah 17,44\%. Jenis A. marina ditemukankan pada semua stasiun dan semua plot, sedangkan A. lanata

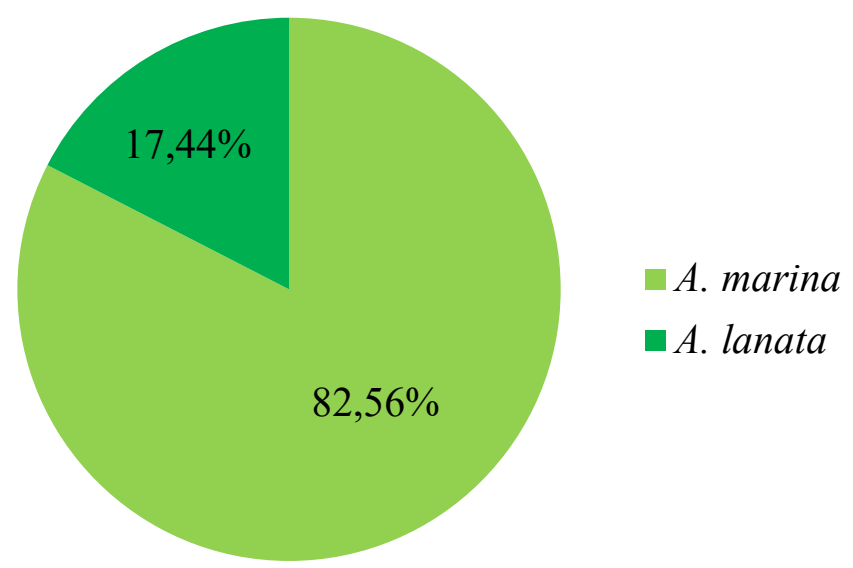

Gambar 2. Komposisi jenis mangrove tingkat pohon 


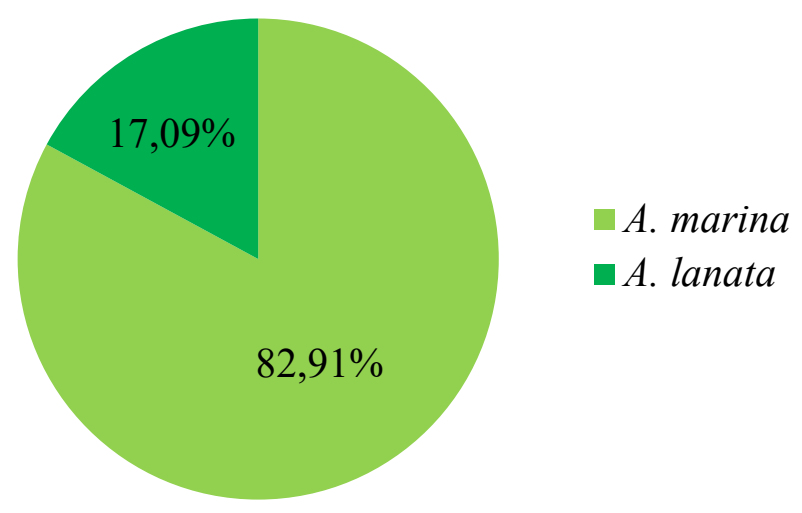

Gambar 3. Komposisi jenis mangrove tingkat pancang

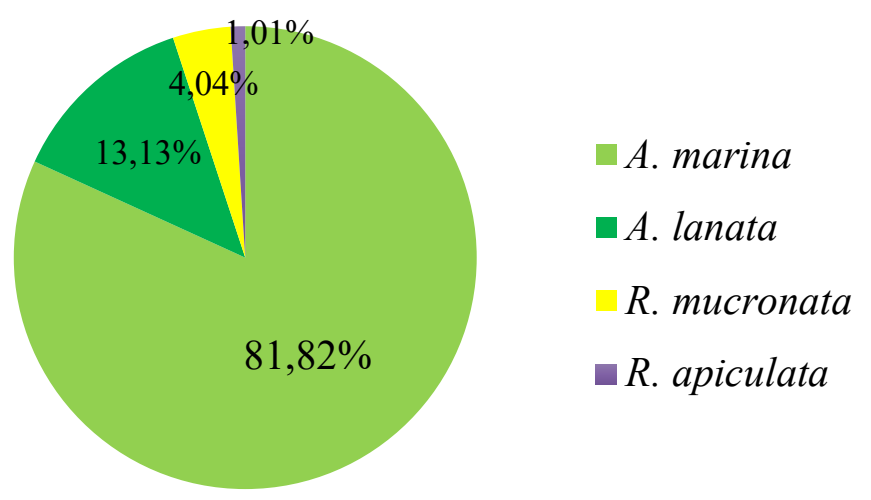

Gambar 4. Komposisi jenis mangrove tingkat semai

hanya ditemukan pada stasiun I plot 2 dan 3 , stasiun II plot 2, dan stasiun III plot 3, 4 dan 5 . Jenis mangrove A. marina memiliki persentase tertinggi karena mampu beradaptasi dengan baik terhadap kondisi lingkungan dan substrat dengan jenis campuran tanah liat dan lempung berlanau sering ditumbuhi A. marina (Kamalia et al., 2012).

Kerapatan jenis pada stasiun I yang ditemukan mangrove jenis $A$. marina dengan nilai kerapatan sebesar 800 pohon/ha dan $A$. lanata 33,33 pohon/ha. Jenis mangrove pada stasiun II hanya terdapat $A$. marina yang memiliki kerapatan tingkat pohon dengan memiliki nilai 950 pohon/ha. Kerapatan tertinggi pada stasiun III yaitu A. marina sebesar 560 pohon/ha sedangkan yang terendah A. lanata sebesar 280 pohon/ha. Jenis A. marina memiliki nilai INP tertinggi yaitu 300 $\%$. Tingginya nilai INP jenis ini menandakan mangrove jenis ini mampu beradaptasi dengan baik pada lingkungan di sekitar lokasi penelitian. INP terendah adalah A. lanata yaitu $31,87 \%$.

\subsection{Komposisi mangrove tingkat pancang}

Komposisi jenis pancang yang tertinggi adalah A. marina sebesar $82,91 \%$, sedangkan komposisi pancang terendah adalah 17,09\% . Jenis mangrove $A$. marina dapat ditemukan di semua stasiun dan plot, sedangkan untuk jenis A. lanata dapat ditemukan pada staiun I plot 2 dan 3, stasiun II plot 2, dan stasiun III plot 3, 4 dan 5. Kerapatan jenis tingkat pancang yang tertinggi pada stasiun III adalah jenis A. marina sebesar 6.800 pohon/ha ditemukan pada semua plot sedangkan yang memiliki kerapatan terendah adalah $A$. lanata sebesar 1.733,33 pohon/ha.

Berdasarkan Keputusan Menteri Lingkungan Hidup Nomor 201 tahun 2004, mangrove tingkat pancang dikategorikan baik. INP jenis mangrove tingkat pancang 
Jurnal Laut Khatulistiwa, Vol. 3. No. 3 (Oktober, 2020), Hal. 105-112.

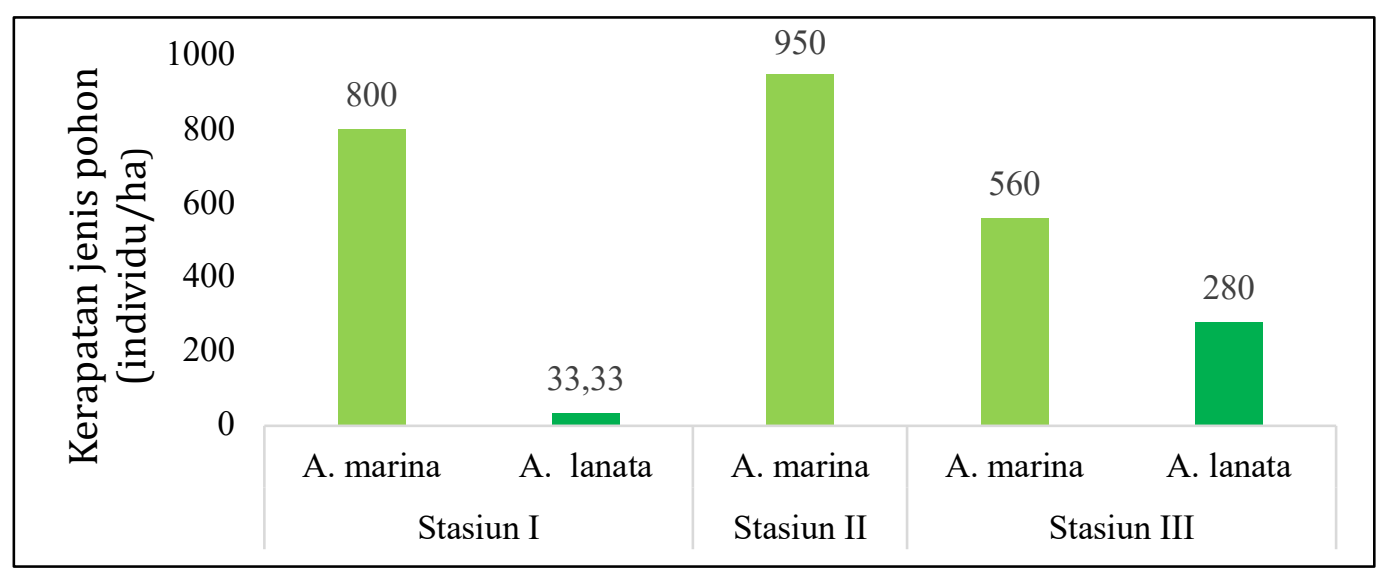

Gambar 5. Kerapatan jenis mangrove tingkat pohon

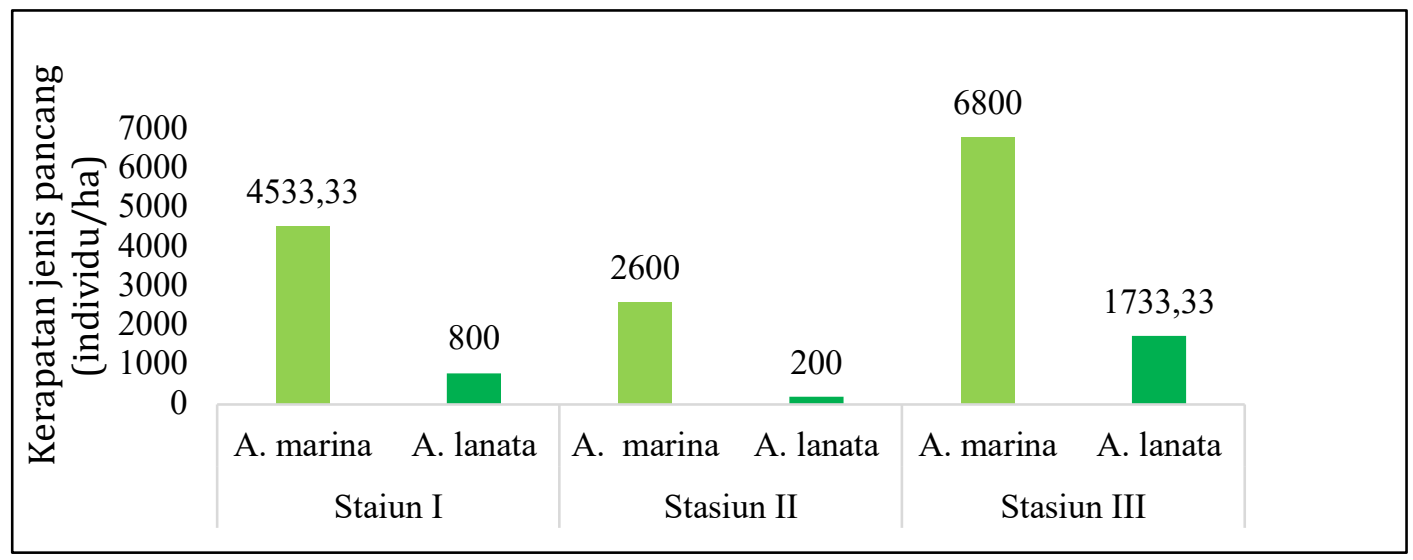

Gambar 6. Kerapatan jenis mangrove tingkat pancang

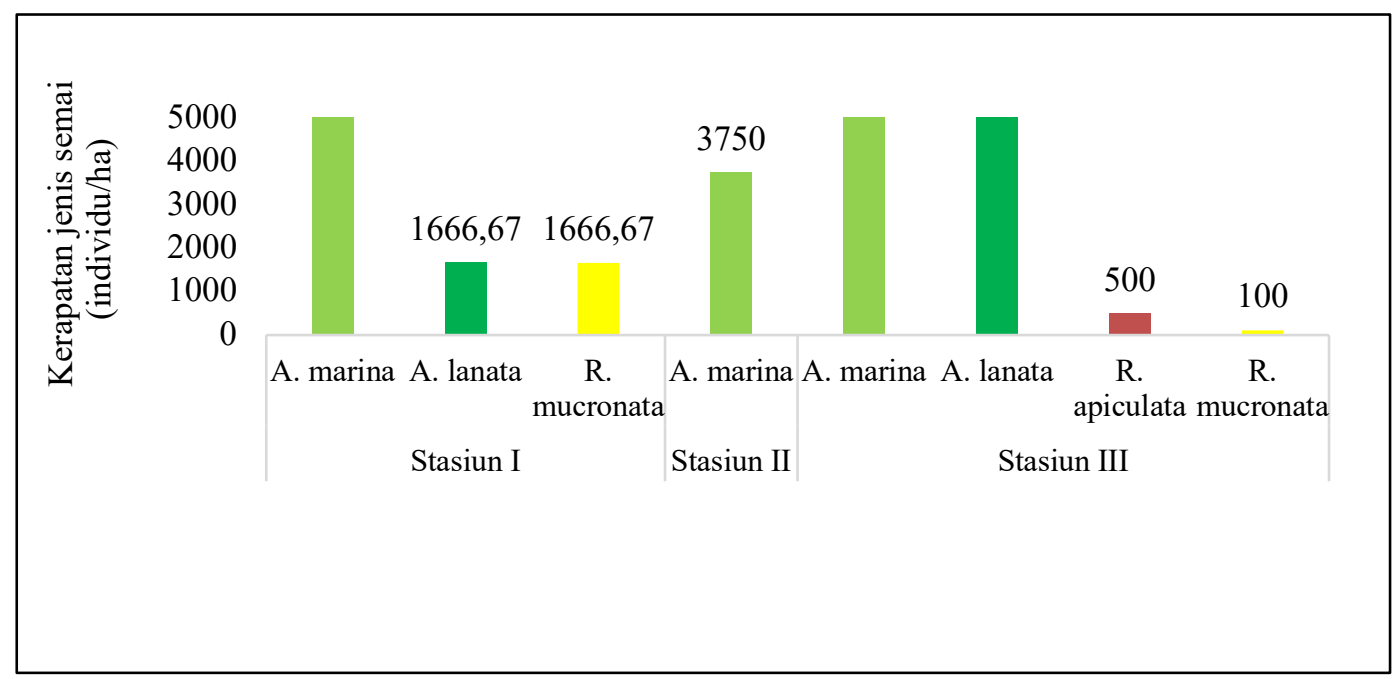

Gambar 7. Kerapatan jenis mangrove tingkat semai

memiliki kisaran $40-160 \%$. INP tertinggi pada tingkat pancang adalah $A$. marina sebesar $160 \%$ pada stasiun I dan terendah $A$. lanata sebesar $40 \%$.

\subsection{Komposisi jenis mangrove tingkat semai}

Komposisi jenis mangrove tingkat semai paling banyak dijumpai adalah $A$. marina dengan persentase sebesar $81,82 \%$ dan 
Jurnal Laut Khatulistiwa, Vol. 3. No. 3 (Oktober, 2020), Hal. 105-112.

Tabel 1. Produksi serasah daun mangrove

\begin{tabular}{cccc}
\hline Stasiun & Plot & $\begin{array}{c}\text { Gram berat basah/15 } \\
\text { hari }\end{array}$ & $\begin{array}{c}\text { Gram berat kering/15 } \\
\text { hari }\end{array}$ \\
\hline I & 1 & 59,80 & 26,87 \\
& 2 & 82,09 & 39,79 \\
& 3 & 138,62 & 85,95 \\
\hline \multirow{2}{*}{ II } & Rata-rata & 93,50 & 50,87 \\
& 1 & 41 & 21,08 \\
\hline \multirow{2}{*}{ III } & 2 & 92,89 & 40,31 \\
& Rata-rata & 75,80 & 37,42 \\
& 1 & 107,06 & 64,09 \\
& 2 & 103,22 & 62,71 \\
& 3 & 123,05 & 81,23 \\
& 4 & 145,19 & 92,68 \\
& 5 & 139,41 & 89,04 \\
\hline
\end{tabular}

Tabel 2. Nilai kandungan karbon

\begin{tabular}{cccc}
\hline Stasiun & Plot & Gram karbon/15 hari & Gram karbon/hari \\
\hline I & 1 & 19,24 & 1,28 \\
& 2 & 29,78 & 1,99 \\
& 3 & 65,75 & 4,38 \\
\cline { 2 - 4 } & Total & 114,77 & 7,65 \\
& Rata-rata & 38,26 & 2,55 \\
\hline II & 1 & 10,70 & 0,71 \\
& 2 & 29,26 & 1,95 \\
\cline { 2 - 4 } & Total & 39,96 & 2,66 \\
& Rata-rata & 19,98 & 1,33 \\
& 1 & 50,96 & 3,40 \\
& 2 & 49,65 & 3,31 \\
& 3 & 61,77 & 4,12 \\
& 4 & 75,93 & 5,06 \\
& 5 & 70,82 & 4,72 \\
\cline { 2 - 4 } & Total & 309,14 & 20,61 \\
& Rata-rata & 61,83 & 4,12 \\
\hline
\end{tabular}

tingkat persentase terendah adalah $R$. apiculata sebesar 1,01\%. A. marina ditemukan pada stasiun I plot 1 dan 3 , stasiun II plot 2, dan stasiun III plot 1, 2, 3, dan 5 . Sedangkan R. apiculata hanya ditemukan pada stasiun III plot 1. Kerapatan mangrove yang tertinggi pada tingkat semai adalah A. marina sebesar 43.333 pohon/ha yang ditemukan pada stasiun I. Berdasarkan Keputusan Menteri Lingkungan Hidup Nomor 201 tahun 2004 mangrove tingkat semai dikategorikan baik.

\subsection{Keanekaragaman jenis mangrove}

Keanekaragaman tingkat pohon di Kuala Singkawang Kalimantan berkisar $0-0,64$. Keanekaragaman jenis mangrove tingkat pohon memiliki nilai yang tinggi ditemukan pada stasiun III yaitu 0,64, Indeks keanekaragaman tingkat pancang dilokasi penelitian berkisar 0,42-0,54, dan stasiun III memiliki nilai indeks keanekaragaman yang tinggi yaitu 0,88.. Hal ini menunjukan bahwa keanekaragaman tingkat pohon pada hutan mangrove Kuala Singkawang tergolong rendah.

\subsection{Nilai parameter lingkungan}


Kisaran nilai salinitas yang diperoleh pada masing-masing stasiun pengamatan adalah 7$25 \%$, Nilai suhu perairan di stasiun I, II, dan III pengamatan adalah $30^{\circ} \mathrm{C}$ sedangkan suhu perairan sungai antara $29^{\circ} \mathrm{C}-30^{\circ} \mathrm{C}$. Berdasarkan Keputusan Menteri Lingkungan Hidup Nomor 51 tahun 2004, suhu yang baik bagi pertumbuhan mangrove berkisar antara $28-30^{\circ} \mathrm{C}$

Nilai DO ekosistem mangrove pada stasiun pengamatan berkisar antaa 4,1-7,1 $\mathrm{mg} / \mathrm{L}$. Berdasarkan Keputusan Menteri Lingkungan Hidup Nomor 51 tahun 2004, nilai DO yang baik bagi pertumbuhan mangrove $>5 \mathrm{mg} / \mathrm{l} \mathrm{hal}$ ini di tunjukan pada stasiun I, II, dan III.

Derajat keasaman $(\mathrm{pH})$ tanah sekitar mangrove pada lokasi pengamatan menunujukan nilai yang relatif sama pada 3 stasiun yaitu 8 , sedangkan nilai $\mathrm{pH}$ perairan memiliki rentang 4,1-6,3. Hilmi (2005) menyatakan bahwa kisaran pH antara 6,0-6,5 merupakan $\mathrm{pH}$ yang cukup netral yang dapat mendukung kehidupan mangrove secara optimal. Jenis substrat di daerah mangrove Kuala Singkawang Kalimantan Barat adalah pada stasiun I dan II campuran tanah liat dan berlempung lanau sedangkan pada stasiun III tanah liat berlempung.

\subsection{Laju produksi karbon serasah daun mangrove}

Serasah daun mangrove yang didapatkan pada lokasi penelitian adalah serasah daun mangrove A. marina dan A. lanata. Hal ini disebabkan karena mangrove jenis R. apiculata dan R. mucronata masih dalam tingkat semai. Hasil sersasah basah daun mangrove yang didapatkan pada lokasi penelitian berkisar 4192,68 sedangkan berat serasah kering berkisar 21,08-92,68 g.

Hasil produksi serasah daun mangrove berat basah yang tertinggi didapatkan pada stasiun III yaitu dengan nilai rata-rata 135,88 g dan rata-rata terendah pada stasiun II yaitu sebesar 75,80 g. Dan produksi berat kering serasah daun mangrove yang memiliki nilai tertinggi terdapat pada stasiun III yaitu $87,65 \mathrm{~g}$ dan nilai rata-rata terendah terdapat pada stasiun II yaitu $37,42 \mathrm{~g}$.

Kondisi ini dapat terjadi karena nilai kerapatan jenis stasiun II lebih kecil dibandingkan dengan stasiun III. Perbedaan hasil yang didapatkan berperanguh dengan kerapatan pohon mangrove. Menurut Rositah et al. (2013) semakin rapat tegakan pohon mangrove jumlah produksi serasah juga semakin banyak, maka kandungan karbon pada serasah juga semakin tinggi.

Faktor lingkungan juga mempengaruhi hasil produksi serasah seperti suhu dan salinitas. Salah satu bentuk adaptasi tumbuhan mangrove untuk mengurangi kehilangan air agar dapat bertahan hidup pada kondisi kadar garam tinggi yaitu dengan menggugurkan daunnya (Murdiyanto, 2003) dan tumbuhan mangrove akan menggugurkan daunnya dibawah suhu optimum dan menghentikannya diatas suhu optimum (Farhaby, 2011). Selain itu, faktor pemgambilan serasah daun mangrove akanmempengaruhi produksi serasah.

Nilai kandungan karbon yang didapatkan pada setiap stasiun memiliki nilai kandungan karbon yang berbeda. Nilai rata-rata kandungan karbon tertinggi didapatkan pada stasiun III yaitu $4,12 \mathrm{~g} \mathrm{C} / \mathrm{m}^{2} /$ hari dan terendah didapatkan pada stasiun II yaitu 1,33\% g $\mathrm{C} / \mathrm{m}^{2} /$ ha.

\section{Kesimpulan}

Berdasarkan hasil peneltian dapat disimpulkan bahwa Komposisi jenis mangrove di Kuala Singkawang Kalimantan Barat ditemukan 4 spesies yaitu A. marina, A. lanata $R$. apiculata dan $R$. mucronata. Keanekaragaman jenis mangrove di Kuala Singkawang Kalimantan Barat tergolong masih rendah. Dan Laju produksi karbon serasah daun mangrove di Kuala Singkawang Kalimantan Barat didapatkan pada stasiun III plot 4 sebesar 5,06\% g C/m²/hari $(1.846,9 \mathrm{~g}$ $\mathrm{C} / \mathrm{m}^{2} /$ tahun) dan terendah didapatkan pada stasiun II pada plot 2 sebesar $0,71 \% \mathrm{~g}$ $\mathrm{C} / \mathrm{m}^{2} /$ hari $\left(259,15 \mathrm{~g}^{\mathrm{r}} / \mathrm{m}^{2} /\right.$ tahun $)$.

\section{Ucapan Terima Kasih}

Penulis mengucapkan terimakasih kedapa Kementerian Riset, Teknologi dan Pendidikan Tinggi Republik Indonesia atas program Beasiswa Bidikmisi sehingga penulis dapat menyelesaikan riset di FMIPA UNTAN.

\section{Daftar Pustaka}

Alongi, D. M., 2002, Present State and Future of 
the world's.

Alongi, D. M.; .; Pfitzner, J.; Trott, L.A.; Tirendi, F.; Dixon, P. and Klumpp, D.W.,2005, Rapid Sediment Accumulation And Microbial Mineralization In Forests of The Mangrove Kandelia Candel In The Jiulongjiang Estuary, China, Estuar, Coast, Shelf Sci, 63.605- 618.

Bunt J.S., 1995, Continental Scale Patterns In Mangrove Litterfall, Mangrove Forest, J. Environment and Conservation, 29:331349.

Dharmawan.; I. W. E.; Zamani, N. P. dan Madduppa, H. H., 2016, Laju Dekomposisi Serasah Daun di Ekosistem Bakau Pulau Kelong, Kabupaten Bintan, J. Oseanologi dan Limnologi di Indonesia., Vol 1. No.1: Hal 1-10.

Donato, D. C.; Kauffman, J. B.; Mudiyarso, D.; Kurnianto, S.; Stidham, M. dan Kanninen, M., 2011, Mangrove Among the Most Carbon-rich Forest in the Tropics. J. Nature Geosciense, 4(5): 293-297.

Farhaby, A.M., 2011, Kerapatan Tegakan Mangrove dan Kelimpahan Kepiting Bakau (Scylla sp) di Kawasan Ujung Alang Segara Anakan Cilacap, Universitas Diponegoro.

Hamidy, R. S.; Sastrodiharjo.; Ardianto. dan Taufiturrahman., 2002, Struktur Komunitas dan Produksi Serasah Mangrove di Dumai Riau, Biologi 2(13):755-768.

Hilmi, E., 2003, Model Penduga Kandungan Karbon pada Pohon Kelompok Jenis Rhizophora sp. dan Bruguiera sp. dalam Tegakan Hutan Mangrove, Sekolah Pasca Sarjana Institut Pertanian Bogor, 170 (Disertasi).

Kamalia, T.; S. Raza'i dan T. Efrizal., 2012, Struktur Komunitas Hutan Mangrove di Perairan Pesisir Kelurahan Sawang Kecamatan Kundur Kabupaten Karimun, Fakultas Ilmu Kelautan dan Perikanan Universitas Raja Ali Haji, Kepulauan Riau.

Kementrian Lingkungan Hidup, 2004, Keputusan Menteri Negara Lingkungan Hidup Nomor 201 Tahun 2004 Tentang Kriteria Baku dan Pedoman Kerusakan Hutan Mangrove, Jakarta.

Maiti, S. K. Dan Chowdury, A., 2013, Efects Of Antrophogenic Pollution On Mangrove Biodiversity, Journal of Environmental
Protection., 4: 1428-1434.

Murdiyanto, B., 2003, Mengenal, Memelihara dan Melestarikan Ekosistem Bakau, Direktorat Jenderal Perikanan Tangkap Departemen kelautan dan Perikanan, Jakarta.

McLeod, E. and Salm, R.V., 2006, Managing Mangroves for Resilience to Climate Change, IUCN: Gland, Switzerland.

Metcalfe, K.N.; Franklin, D.C. and McGuinness, K. A., 2011, Mangrove litterfall extrapolation from traps to a large tropical macrotidal harbour, $J$. Estuar Coast Shelf Sci., 95(1):245-252.

Muhtadi, A.; Cordova, M. R. dan Vitner, Y., 2014, Ekosistem Perairan, IPB Perss, Bogor.

Rangkuti, A.M.; Cordova, M.R.; Rahmawati, A.; Yulma, dan Adimu, H.E, 2017, Ekosistem Pesisir dan Laut Indonesia, Bumi Aksara, Jakarta.

Rositah, Herawatiningsih $H_{\text {., }}$ dan Hardiansyah G., 2103, Pendugaan Biomassa Karbon Serasah Dan Tanah Pada Hutan tanaman (Shorea leprosulamiq) Sistem TPTII PT. Suka Jaya Makmur. 1(3):358-366.

Setiawan, H., Dan Mursidi., 2018, Karakteristik Ekologi dan Kesehatan Hutan Mangrove Di Pulau Tanakeke Sulawesi Selatan, J. Penelitian Kehutanan Wallacea, 7(1): 47-58.

Sudarmadji, 1996, Analisa Bahan Makanan dan Pertanian, Liberty, Yogyakarta.

Supriharyono, 2017, Konservasi Ekosistem Sumber Daya Hayati di Wilayah Pesisir dan Laut Tropis, Pustaka Pelajar, Yogyakarta. 